\section{THE ELIMINATION OF POISONS.}

By GEORGE JOHNSON, M.D., F.R.C.P.,

Physician to King's College Hospital ; Professor of Medicine in King's College.

THE elimination of poisons has lately been so fully discussed, that little more remains to be said on the subject ; but a recent paper in the $P$ rac. titioner by Dr. Anstie, in which I am several times personally referred to, calls for a few words of comment. The tone of that paper is, I venture to say, emotional and unscientific. The object of science is, by calm and impartial investigation, to elicit truth; whereas the language of Dr. Anstie is that of one engaged in a fierce strife. The following extract is a specimen. "As such a battle is not won in a single shock, but only by a series of varied and reiterated assaults, I propose to offer my humble contribution to what is (for me) a sacred war." A man who enters upon what he believes to be a crusade, is not likely to be very scrupulous in dealing with his enemies; and accordingly we find that Dr. Anstie begins by attributing to his adversaries opinions which they have repeatedly and strenuously repudiated. He says: "There is no belief more firmly rooted-as I believe there are few more perniciousthan the conviction entertained by a large proportion of medical men that disease is a something of which the body endeavours to rid itself by eliminatory efforts, and that our treatment should be directed to aid these supposed efforts." In this passage, Dr. Anstie confounds disease with a morbific cause. His opponents do not propose to eliminate the disease known by the name of "painters' colic", but the metallic poison which is the cause of the disease. A combatant excited and confused by the din and smoke of battle is not likely to see or appreciate so minute, though essential a distinction as this.

He remarks upon the artificial elimination of lead by means of iodide of potassium, that it "seems expressly calculated to remind us that Nature, if she intended to eliminate the lead at all, has made (anct always does make) a frightful series of blunders in the attempt." Dr. Anstie apparently needs to be reminded that his most formidable opponents are not, as he and his few allies represent them to be, speculative metaphysicians, but practical physiologists, who look upon the whole series of phenomena attending the absorption, the diffusion, and the elimination of poisons as the result of ordinary physiological processes. To speak of the deposit of lead in the tissues as one of "a frightful series of blunders", is about as reasonable and appropriate as to refer to the crushing of a passenger by a falling rock, as an instance of Nature's ferocity. The diffusion of poisons into the tissues and the falling of a rock are equally the result of natural forces and what we call natural laws. If Nature were an abstract entity, endowed with intelligence and with protective power, she would display her wisdom and beneficence rather by preventing the absorption of poisons than by their expulsion or their decomposition after they have entered the system. It is only of late that Dr. Anstie and his friends have resorted to the device of imputing to those who use the term Nature as commonly understood to express the functions of the living body, a belief in an intelligent metaphysical entity. Those who employ this term to avoid periphrasis, attach to it, I imagine, the same meaning as that which is implied in the following extract from one of Dr. Anstie's works. "Today we are inclined to take a less exalted view of our functions, to confess ourselves to be but the humble assistants in those curative processes which Nature herself initiates, and very often carries through without our help, or even in spite of our ignorant interference." It is amusing to contrast the terms in which Nature is spoken of in the two passages which I have quoted from Dr. Anstie ; and it would be interesting to know when he so entirely changed his opinion as to the relative influence of Nature and Art in the cure of disease.

Dr. Anstie refers to a paper by Dr. Dupré, who appears to have proved that, when poisonous doses of alcohol are taken, only minute quantities are eliminated, the greater part being either assimilated or decomposed within the system. I have never laid special stress upon the elimination of alcohol ; but, relying upon the experiments and conclusions of others, including those of Dr. Anstie himself, I have supposed that a considerable proportion of a poisonous dose of alcohol is eliminated by various channels. It now appears, by his own statement, that Dr. Anstie's earlier experiments were erroneous, and his conclusions misleading; but I am at a loss to see in what way this affects the general doctrine of the elimination of poisons. We know that recovery from alcoholic intoxication occurs more rapidly and completely than from most other forms of poisoning. A poison which is capable of being rapidly oxidised and decomposed is more speedily got rid of than one which resists decomposition, and therefore requires to be excreted. No one doubts that some poisons are in part decomposed and in part ejected. We are now told that an excess of alcohol is mainly disposed of by decomposition. Upon this subject, however, we have had so many contradictory assertions, that we shall require some confirmation of the latest statement before we accept it as conclusive.

The pathologist who sees the destructive effect of excess of alcohol upon the secreting tissues of the liver and kidneys, will not readily be convinced that poisonous doses of that agent are almost entirely decomposed into carbonic acid and water. If only minute traces of alcohol pass off by these excretory channels, then it is certain that some products of alcoholic intoxication, other than carbonic acid and water, must excite the glandular changes which occur during the process of excretion. Dr. Anstie, in a recent review article, expresses his conviction that the generally accepted doctrine of the intimate relation between alcoholic excess and cirrhosis of the liver, is erroneous. In this opinion, however, few physicians of experience will be found to agree. I am convinced by long and careful observation, that excess of alcohol is, either directly or indirectly, a fruitful source of both hepatic and renal disease ; and that such disease is the immediate result of the excretion of alcohol and its products by the liver and kidneys.

\section{REMOVAL OF THE UVULA.}

\section{By E. NOBLE SMITH, L.R.C.P., M.R.C.S., L.M., Paddockhurst.} II.

Although I have never witnessed serious bleeding as the result of removal of the uvula, I nevertheless consider it judicious, before proceed. ing to perform the operation, to provide means for arresting hæmorrhage. No one is justified in cutting off this organ, unless able to stop any excessive bleeding that may occur.

I will now describe my usual mode of removing the uvula. I place the patient in a good light, use an ordinary pair of dressing forceps in the place of a spatula, for depressing the tongue, seize the extremity of the uvula, draw the organ forward, and cut it across at the desired place with a pair of scissors, taking care that the wound shall have a backward direction, that it may not be irritated by food swallowed during the pro. cess of healing.

I then desire the patient to gargle his throat with cold water, and, in a few moments, the slight bleeding will have ceased, and the operation be ended. For a few days the patient should restrict himself to cold food, and be careful to avoid exposure to cold. Should the hæmorrhage continue, the wound should be touched, by means of a brush, with the strong solution of perchloride of iron, which failing, a ligature should be resorted to. For this purpose will be required a pair of vulsellum-forceps, and a stem of wood or whalebone, about eight inches in length, pierced at one extremity for attaching a piece of very thin silver wire, which should be formed into a small loop.

To accomplish the desired end, the wire-loop should be placed over the bleeding portion, which should be seized with the forceps drawn downwards, and the wire twisted up tightly, so as to form a ligature. The forceps should then be disengaged, and the wire severed from the stem.

Entire removal is advisable in all cases, except perhaps, where, from excessive vascularity, or from some other unusual condition, there is reason to fear troublesome hæmorrhage: the operator may then leave the smallest possible portion as a stump, which can be ligatured with greater ease, and the patient, moreover, will suffer less pain. Practically, this operation is an entire removal.

In order to diminish the chances of excessive hæmorrhage, I had a wire écraseur constructed for removing the uvula ; but fearing that the tearing process of the instrument, acting upon structures so delicate as those of the soft palate, would probably cause considerable pain and inflammation, I determined to satisfy myself of its effect before advising a patient to submit to the operation. To do this I removed my own uvula, but not without some difficulty, and decided pain; I had to employ considerable force, and a wound was left which, of course, did not have a backward direction. The result of my operation was far from favourable: the subsequent pain was very annoying, I could scarcely swallow any food whatever for several days, and fully a week elapsed before I had recovered sufficiently to eat and drink with comfort.

This mode of operating I cannot recommend. Nothing can better excision with scissors in the manner described above; but $I$ should advise the surgeon always to have in readiness some of the strong solution of iron, and the apparatus for applying a ligature.

Many cases have come to my knowledge, in which operations upon the uvula have terminated in an unsatisfactory manner. This result I have invariably traced to one of two causes; either the portion removed has been insufficient, or the case has not been a proper one for excision. 